\title{
Obesity-Induced Endoplasmic Reticulum Stress Causes Lung Endothelial Dysfunction and Promotes Acute Lung Injury
}

\author{
Dilip Shah ${ }^{1}$, Freddy Romero ${ }^{1}$, Zhi Guo ${ }^{1}$, Jianxin Sun ${ }^{1}$, Jonathan $\mathrm{Li}^{1}$, Caleb B. Kallen ${ }^{2}$, Ulhas P. Naik ${ }^{3}$, and \\ Ross Summer ${ }^{1}$ \\ ${ }^{1}$ Center for Translational Medicine and Jane and Leonard Korman Lung Center, ${ }^{2}$ Department of Obstetrics and Gynecology, \\ and ${ }^{3}$ Cardeza Center for Vascular Biology Research, Thomas Jefferson University, Philadelphia, Pennsylvania
}

\begin{abstract}
Obesity is a significant risk factor for acute respiratory distress syndrome. The mechanisms underlying this association are unknown. We recently showed that diet-induced obese mice exhibit pulmonary vascular endothelial dysfunction, which is associated with enhanced susceptibility to LPS-induced acute lung injury. Here, we demonstrate that lung endothelial dysfunction in diet-induced obese mice coincides with increased endoplasmic reticulum (ER) stress. Specifically, we observed enhanced expression of the major sensors of misfolded proteins, including protein kinase R-like ER kinase, inositol-requiring enzyme $\alpha$, and activating transcription factor 6 , in whole lung and in primary lung endothelial cells isolated from dietinduced obese mice. Furthermore, we found that primary lung endothelial cells exposed to serum from obese mice, or to saturated fatty acids that mimic obese serum, resulted in enhanced expression of markers of ER stress and the induction of other biological responses that typify the lung endothelium of diet-induced obese mice, including an increase in expression of endothelial adhesion molecules and a decrease in expression of endothelial cell-cell junctional proteins. Similar changes were observed in lung endothelial cells and in whole-lung tissue after exposure to tunicamycin, a compound that causes ER stress by blocking $\mathrm{N}$-linked glycosylation, indicating that ER stress causes endothelial dysfunction in the lung. Treatment with 4-phenylbutyric acid,
\end{abstract}

a chemical protein chaperone that reduces ER stress, restored vascular endothelial cell expression of adhesion molecules and protected against LPS-induced acute lung injury in diet-induced obese mice. Our work indicates that fatty acids in obese serum induce ER stress in the pulmonary endothelium, leading to pulmonary endothelial cell dysfunction. Our work suggests that reducing protein load in the ER of pulmonary endothelial cells might protect against acute respiratory distress syndrome in obese individuals.

Keywords: obesity; saturated fatty acid; endoplasmic reticulum stress; acute respiratory distress syndrome; acute lung injury

\section{Clinical Relevance}

Obesity is a significant risk factor for acute respiratory distress syndrome. Our work indicates that elevated levels of saturated fatty acids in the serum of obese mice cause pulmonary endothelial cell dysfunction by inducing endoplasmic reticulum stress and suggest that strategies that reduce protein load in the endoplasmic reticulum of the lung endothelium might be effective in protecting against developing acute respiratory distress syndrome in the obese.
Obesity is a significant risk factor for acute respiratory distress syndrome (ARDS): the mechanisms underlying this association remain poorly understood $(1,2)$. We recently reported that diet-induced obesity leads to profound changes in the vascular endothelium of the mouse lung, including enhanced expression of leukocyte adhesion proteins and decreased expression of endothelial junctional proteins (3). These cellular changes were associated with an increased susceptibility to acute lung injury (ALI) in obese mice. Our findings suggested that obesity renders the lung more susceptible to ARDS by adversely affecting

(Received in original form September 28, 2016; accepted in final form January 31, 2017)

This work was supported by National Institute of Health grant R01HL105490.

Author Contributions: Conceived and designed the experiments-D.S. and R.S.; performed experiments-D.S., F.R., Z.G., and J.L.; analyzed the data-D.S.; wrote the manuscript-D.S. and R.S.; edited the manuscript-J.S., C.B.K. and U.P.N.; supervised the entire project-R.S.

Correspondence and requests for reprints should be addressed to Ross Summer, M.D., Center for Translational Medicine and Jane and Leonard Korman Lung Center, Thomas Jefferson University, 1020 Locust Street, JAH 368-F, Philadelphia, PA 19107. E-mail: ross.summer@jefferson.edu

This article has an online supplement, which is accessible from this issue's table of contents at www.atsjournals.org

Am J Respir Cell Mol Biol Vol 57, Iss 2, pp 204-215, Aug 2017

Copyright @ 2017 by the American Thoracic Society

Originally Published in Press as DOI: 10.1165/rcmb.2016-03100C on March 9, 2017

Internet address: www.atsjournals.org 
pulmonary vascular endothelial cell functions.

Emerging evidence indicates that chronically elevated levels of fatty acids contribute to organ dysfunction in obesity (4-7). Once adipose tissues become sufficiently expanded in obese individuals, alternative tissues appear to serve as reservoirs for surplus dietary lipids, resulting in widespread tissue inflammation and disruption of numerous cellular functions. Cellular functions that are particularly vulnerable to the "lipotoxic" effects of fatty acids include the synthesis, folding, and secretion of proteins by the endoplasmic reticulum (ER) $(8,9)$. This vulnerability may reside in the effects that lipids exert on membrane fluidity, which, in turn, modulates protein trafficking and function in the ER. Mechanisms notwithstanding, it is now recognized that the accumulation of misfolded/unfolded proteins within the ER, termed "ER stress," is a pathological feature observed in many tissues adversely affected by obesity. Moreover, ER stress has been implicated in the pathogenesis of several obesity-related conditions, including insulin resistance, atherosclerosis, and hepatic steatosis, to name a few (10-12).

Because protein accumulation in the ER can be damaging to essential ER functions, and therefore to cellular/tissue health, mammalian cells have evolved compensatory responses to excessive protein loads, collectively termed the "unfolded protein response" (UPR) $(10,12)$. The UPR is activated by three specialized molecular sensors: protein kinase R-like ER kinase (PERK), inositolrequiring enzyme (IRE) 1, and activating transcription factor (ATF) 6, each of which straddles the ER membrane and undergoes conformational changes when exposed to high concentrations of abnormally folded proteins from within the ER lumen. These conformational changes trigger numerous downstream signaling pathways engineered to alleviate protein load by halting transcription, slowing translation, and targeting misfolded proteins for degradation. That said, chronic activation of the UPR can deleteriously affect tissue functions by activating inflammatory pathways linked to several UPR effector proteins. It is the chronic activation of these inflammatory pathways that is responsible for causing or exacerbating many obesity-related conditions $(13,14)$.
We reasoned that many of the deleterious effects that obesity exerts on systemic vascular cells might similarly impair the function of pulmonary vascular endothelial cells. We tested the hypothesis that obesity impairs vascular function in the lung by inducing ER stress in the pulmonary endothelium. Having confirmed this hypothesis, we next tested whether reducing ER stress protects obese mice from their enhanced susceptibility to ALI. We observed that inhibiting ER stress in obese mice protects against ALI and may represent an important therapeutic strategy for preventing ARDS in obese humans who are at risk for ALI. Of note, some of the results presented here have previously been reported in the form of an abstract (15).

\section{Materials and Methods}

\section{Mice Studies}

Male 3-week-old AKR/J mice were purchased from the Jackson Laboratory (Bar Harbor, ME) and housed under standard 12-hour light/dark conditions. Mice were fed either a normal chow diet $(13.5 \%$ calories from fat, $58 \%$ from carbohydrates, and $28.5 \%$ from protein) or a high-fat diet (HFD)/Western-style diet (TD.08811, $45 \%$ calories from fat; Envigo, East Millstone, NJ) for a total of 14 weeks. Daily intraperitoneal injections of 4-phenylbutyric acid (4-PBA; $0.5 \mathrm{~g} / \mathrm{kg} / \mathrm{d}$ ) were administered for a total of 14 days in a subset of diet-induced obese mice to reduce ER stress, whereas a subset of lean mice received twice-weekly intratracheal injections of tunicamycin for a total of 2 weeks to generate ER stress (16). All experimental protocols were approved by the Thomas Jefferson University (Philadelphia, PA) Institutional Animal Care and Use Committee before initiating any studies.

\section{Murine Model of ALI}

ALI was induced as previously described (17). In brief, a one-time dose of LPS $(100 \mu \mathrm{g})$ or isotonic saline was instilled into the posterior oropharyngeal space of anesthetized mice while the tongue was gently extracted with tweezers to facilitate fluid entry into the lung.

\section{Analysis of Bronchoalveolar Lavage Fluid}

Bronchoalveolar lavage (BAL), total cell counts, differential cell counts, and total protein concentration determination in the BAL fluid were performed as previously described (17).

\section{ELISA}

Levels of the proinflammatory cytokines, TNF- $\alpha$ and IL- 6 , were determined in the lungs using a commercially available ELISA kit (R\&D Systems, Minneapolis, MN), whereas BAL fluid IgM protein was quantified using a commercially available ELISA kit (Abcam, Cambridge, MA) according to the manufacturer's instructions, as previously described (18).

\section{Analysis of Serum-Free Fatty Acid Level}

Serum free fatty acid (FFA) levels were measured using a commercially available kit (Biovision, Mountain View, CA) according to the manufacturer's instructions.

\section{Gene Expression Analysis by Real-Time PCR}

$\mathrm{C} / \mathrm{EBP}$ homologous protein (CHOP) and 78 $\mathrm{kDa}$ glucose-regulated protein (GRP78) were the gene transcripts evaluated in this study. The housekeeping gene, Hprt1, was used for normalization. See the MAterials AND METHODS section in the online supplement for specific details regarding quantitative RT-PCR.

\section{Western Blotting}

Western blot analysis was performed for GRP78, ATF6, phosphorylated (p)-PERK, PERK, p-eukaryotic initiation factor $2 \alpha$ (eIF2 $\alpha$ ), elF2 $\alpha$, IRE1 $\alpha$, CHOP, intercellular adhesion molecule 1 (ICAM-1), vascular cell adhesion molecule 1 (VCAM-1), E-selectin, vascular endothelial cadherin (VE-Cad), p-VE-cadherin, $\beta$-catenin, sarcoma kinase (Src), p-Src (Tyr416), glyceraldehyde phosphate dehydrogenase, and $\beta$-actin. Protein bands were visualized using the Odyssey infrared imaging system (Li-Cor Biosciences, Lincoln, NE). The protocols are described in the MATERIALS AND Methods section in the online supplement.

\section{Immunohistochemistry}

Immunohistochemical staining was performed on deparaffinized lung sections for anti-Gr1 staining, as previously described (18).

\section{Lung Endothelial Cell Isolation}

Lung tissue was dissociated into a single-cell suspension using a mouse lung dissociation kit (Miltenyi Biotec, Bergisch Gladbach, Germany) with the gentle gentleMACS dissociator (Miltenyi Biotec, Bergisch Gladbach, Germany), as previously 
described (19). The purity of the endothelial cell population was confirmed by flow cytometry, as previously described (17).

\section{Cell Culture}

Human lung microvascular endothelial cells and medium were purchased from ScienCell Research Laboratory (Carlsbad, CA). Cells were used for no more than five passages. Human lung microvascular endothelial cells were cultured with serum from lean or obese mice $(10 \mu \mathrm{l} / \mathrm{ml}$ medium $)$ for some studies.

\section{Preparation of Fatty Acid-Bovine Serum Albumin Complex}

The fatty acid-bovine serum albumin (BSA) complex used in experiments was prepared according standard protocol (20). Cells were exposed to the FFA palmitate (PA) or oleic acid (OA) complexed to BSA in a ratio of 6:1 (FFA:BSA) in full culture medium. BSA alone was used as a control and PA plus OA were added to culture media for some studies.

\section{In Vitro Endothelial Permeability Assay}

In vitro endothelial permeability assay was performed as described previously (19).

\section{Statistical Analysis}

Statistics were performed using GraphPad Prism 5.0 software (GraphPad Software Inc., La Jolla, CA). Two-group comparisons were analyzed by unpaired Student's $t$ test, whereas multiple-group comparisons were performed using one-way ANOVA followed by Tukey's post hoc analysis. Statistical significance was achieved when $P$ was less than 0.05 at $95 \%$ confidence interval.

\section{Results}

\section{Obesity Induces ER Stress in the Lung Endothelium}

To assess whether obesity induces ER stress in the pulmonary endothelium, we compared levels of ER stress markers in whole-lung tissues from AKR/J mice fed a normal diet or HFD for a total of 14 weeks. The decision to select the AKR/J strain was based on our prior work, which demonstrated that an HFD severely impairs lung endothelial homeostasis in these mice (3). As expected, mice on the HFD became obese (Figure 1A). We found that transcript and protein levels for various ER stress markers were significantly up-regulated in whole-lung tissues from diet-induced obese mice as compared with lean controls. Each of the three major sensors of misfolded proteins, ATF6, PERK, IRE1 $\alpha$, as well as the related UPR molecules, elF $2 \alpha$, CHOP, and the chaperone protein, GRP78 (Figures $1 \mathrm{~B}-1 \mathrm{D})$, were elevated in the obese mouse lungs. More importantly, we found that levels of ATF6, p-PERK/PERK, p-elF $2 \alpha /$ elF $2 \alpha$, IRE $1 \alpha$, and CHOP proteins were also up-regulated in freshly isolated endothelial cells from the lungs of diet-induced obese mice, providing direct evidence that obesity induces ER stress in the pulmonary vascular endothelium (Figure 1E).

\section{Systemic Inflammation Promotes ER Stress in Cultured Lung Endothelial Cells}

Elevated concentrations of systemic fatty acids are thought to induce ER stress in obese individuals $(14,21,22)$. We reasoned that chronic exposure to elevated circulating FFAs might promote ER stress in the lung endothelium. We first confirmed that circulating FFA levels are nearly twofold elevated in the serum of diet-induced obese mice relative to lean controls (Figure 2A). We next exposed human microvascular lung endothelial cells to media containing serum from either lean or obese mice and measured expression of several markers of ER stress. We found that serum from obese mice enhanced the expression of the UPR markers, ATF6, p-PERK/PERK, IRE $1 \alpha$, and p-elF $2 \alpha / \mathrm{elF} 2 \alpha$, when compared with serum from lean controls (Figure 2B). These findings were associated with additional cellular changes that typify the lung endothelium of diet-induced obese mice, including enhanced expression of ICAM1, VCAM1, E-selectin, activation of Src kinase (phosphorylation of $\mathrm{Y}^{416}$ ), increased expression of $\mathrm{p}$-VEcadherin relative to total VE-cadherin, and decreased expression of $\beta$-catenin (Figures 2C and 2D). These data confirm that serum from obese mice induces ER stress along with gene expression changes characteristic of endothelial dysfunction in primary pulmonary endothelial cells.

To test our hypothesis that elevated concentrations of fatty acids induce ER stress in the lung endothelium, we exposed lung endothelial cells to physiological concentrations of PA-BSA (6:1 ratio) or BSA alone, and assessed the effects on the expression of ER stress markers. PA was selected based upon evidence linking high levels of saturated fatty acids to ER stress in the liver and adipose tissue of obese mice $(14,21,22)$. We observed a dose-dependent increase in the expression of ATF6, p-PERK/PERK, IRE1 $\alpha$, p-elF $2 \alpha /$ elF $2 \alpha$, CHOP, and GRP78 (Figures 2E and 2F; see also Figure E1 in the online supplement). These findings were associated with enhanced expression of ICAM1, VCAM1, E-selectin, elevated ratios of pSrc to total Src and p-VE-cadherin to total VE-cadherin, and reduced expression of $\beta$-catenin (Figures $2 \mathrm{G}$ and $2 \mathrm{H}$ ), consistent with our observation that ER stress induces functional changes in the lung endothelium. Next, to assess whether cellular changes induced by PA are specific to this type of lipid, we exposed lung endothelial cells to similar concentrations of a mono-unsaturated fatty acid, OA. In contrast to $\mathrm{PA}$, we found that $\mathrm{OA}$ neither induced the expression of UPR proteins nor promoted cellular changes characteristic of dysfunctional lung endothelium observed in diet-induced obese mice (Figure E2). OA did not enhance markers of ER stress or endothelial dysfunction in our assays, even when combined with PA. Strikingly, we observed that OA protects lung endothelial cells, as evidenced by reduced expression of ER stress markers and leukocyte adhesion proteins, and increased expression of junctional adherens proteins after combined treatments with PA plus OA (Figure E2). Overall, these findings support the hypothesis that elevated levels of saturated fatty acids, but not unsaturated fatty acids, contribute to the development of ER stress in the lung endothelium of obese mice.

\section{Protein Misfolding Induces Functional Changes in the Lung Endothelium}

To further establish a mechanistic link between ER stress and homeostatic changes in the lung endothelium, we exposed lung endothelial cells to tunicamycin, a compound that causes ER stress by blocking $\mathrm{N}$-linked glycosylation. Tunicamycin potently induced expression of the ER stress markers, ATF6, p-PERK/PERK, and $\mathrm{p}$-elF $2 \alpha / \mathrm{elF} 2 \alpha$, in cultured lung endothelial cells (Figure 3A). Tunicamycin also resulted 
A

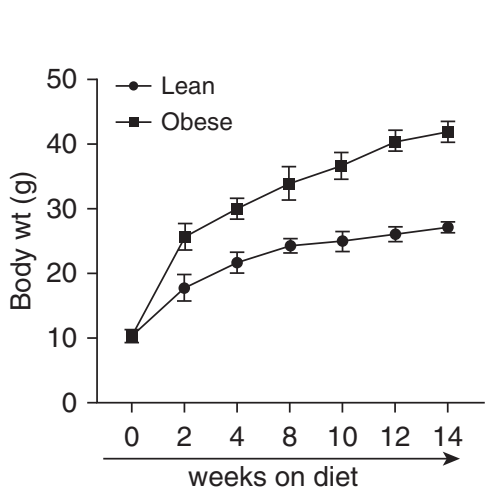

E

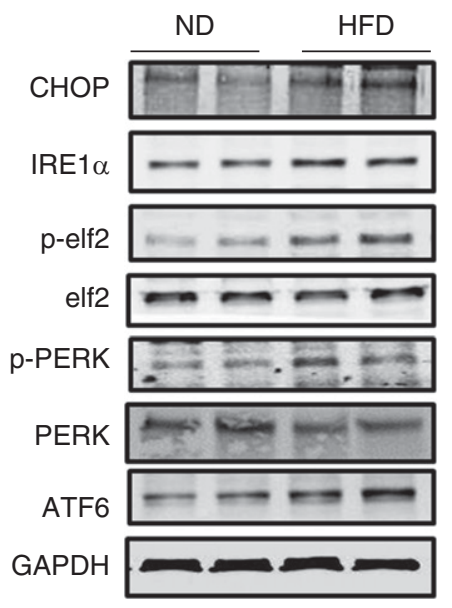

B

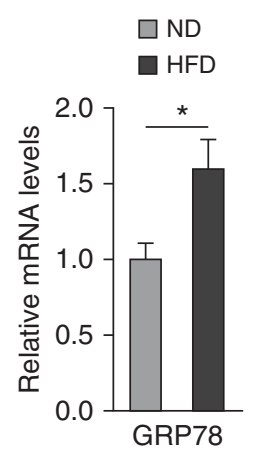

C

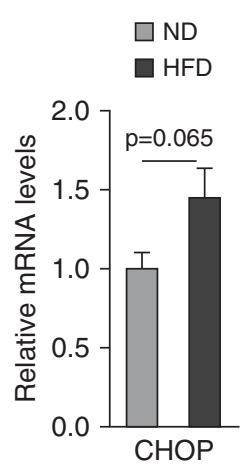

D

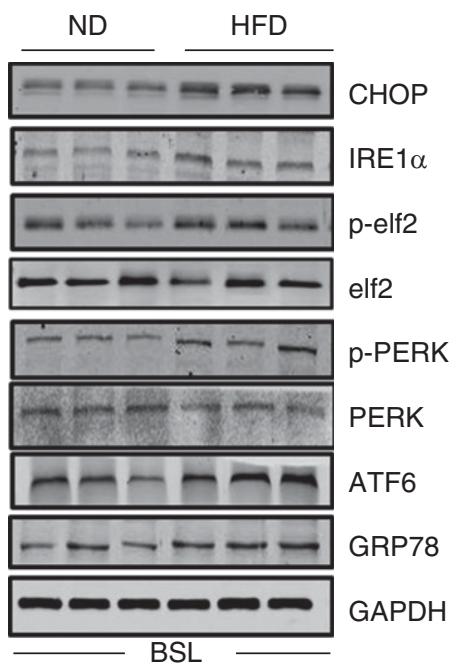

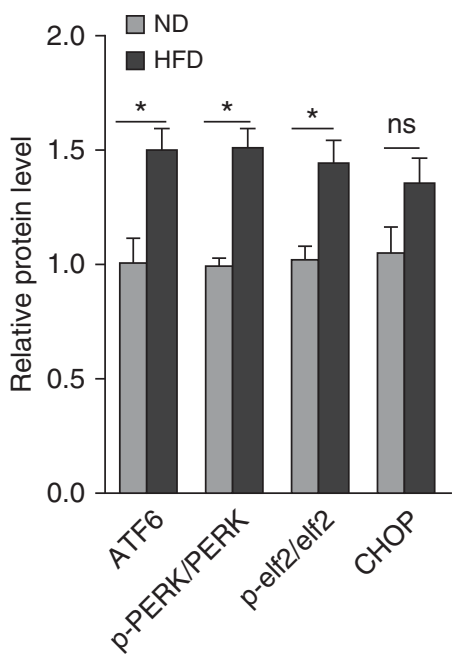

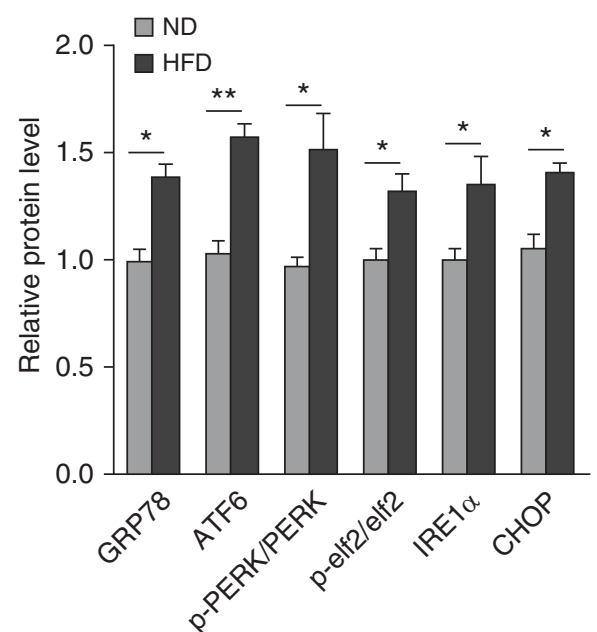

Figure 1. Obesity induces endoplasmic reticulum (ER) stress in lung endothelium. (A) Body weight (wt) of mice fed a normal diet (ND) or high-fat diet (HFD), fed for a total of 14 weeks. (B and C) Transcript levels for 78 kDa glucose-regulated protein (GRP78) (a.k.a., Bip1) and C/EBP homologous protein $(\mathrm{CHOP})$ in whole-lung tissues from lean and obese mice $\left(n=4,{ }^{\star} P<0.05\right.$ versus ND group) at baseline. Western blot analysis for ER stress markers, GRP78, activating transcription factor (ATF) 6, protein kinase R-like ER kinase (PERK), phosphorylated (p)-PERK, eukaryotic initiation factor 2 (elf2), p-elf2, inositol-requiring enzyme (IRE) $1 \alpha$, and CHOP in whole-lung tissues $(D)$ and freshly isolated lung endothelial cells $(E)$ from lean and obese mice. Densitometry analysis is shown below in $D\left(n=6,{ }^{*} P<0.05\right.$ and ${ }^{* *} P<0.01$ versus ND group) and on the right in $E\left(n=4,{ }^{*} P<0.05\right.$ versus ND group). Data are expressed as mean $( \pm \mathrm{SE})$. The statistical significance was assessed using a Student's unpaired $t$ test. ns, not significant. BSL, baseline.

in enhanced endothelial cell expression of ICAM1, VCAM1, and E-selectin, increased the ratio of pSrc to total Src and p-VEcadherin to total VE-cadherin, and reduced expression of $\beta$-catenin (Figure 3B and 3C). Furthermore, intratracheal instillation of tunicamycin in control mice resulted in similar changes in the expression of endothelial adhesion markers and junctional adherens protein in whole lungs and isolated lung endothelial cells (Figures 3D-3G). In aggregate, these findings indicate that various triggers of ER stress in lung endothelium, including obesity and associated levels of saturated fatty acids, converge to disrupt endothelial barrier functions and to promote ALI.

\section{Reducing ER Stress Restores \\ Endothelial Homeostasis in the \\ Lungs of Obese Mice and \\ Protects against ALI}

Because tunicamycin induced cellular changes in the lung endothelium that mimicked those observed in the lungs of diet-induced obese mice, we reasoned that therapies that reduce ER stress might restore endothelial homeostasis in the obese lung. To test this hypothesis, we cultured lung endothelial cells with PBA, a chemical protein chaperone that reduces ER stress by enhancing protein folding capacity, and then measured expression of various UPR proteins after 24-hour exposure to PA. We observed that expression of ATF6, p-PERK/PERK, IRE $1 \alpha$, p-elF2 $\alpha /$ elF2 $\alpha$, CHOP, and GRP78 were all markedly down-regulated in PA-exposed cells after 4-PBA treatment (Figures 4A and 4B). These cellular changes coincided with decreased expression of ICAM, VCAM, and E-selectin, reduced expression of pSrc to total Src and p-VE-cadherin to total VE-cadherin, and increased expression of $\beta$-catenin (Figures $4 \mathrm{C}$ and $4 \mathrm{D}$ ). 
A
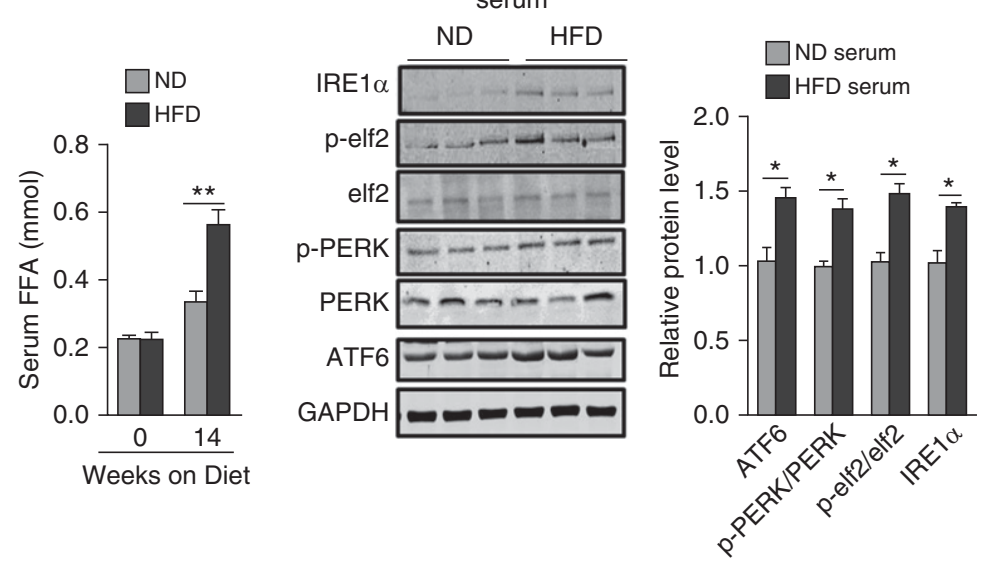

E
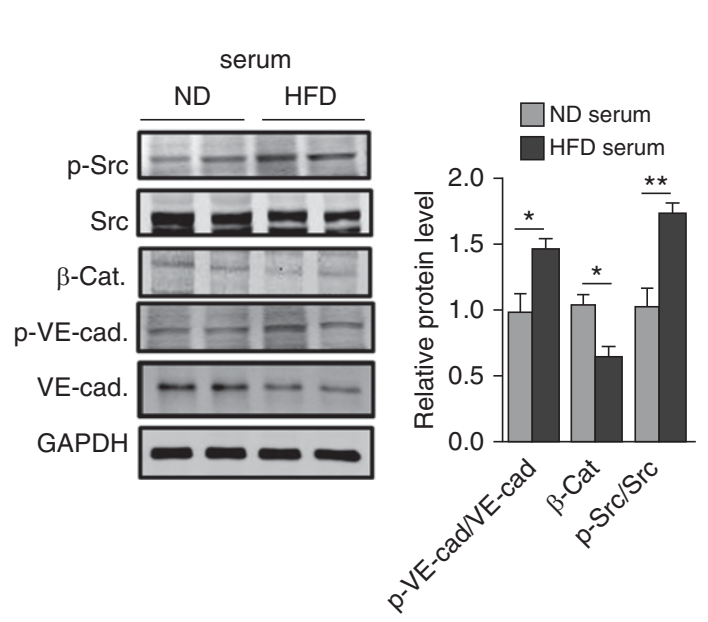

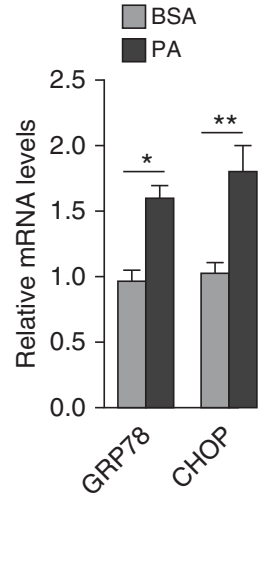

C

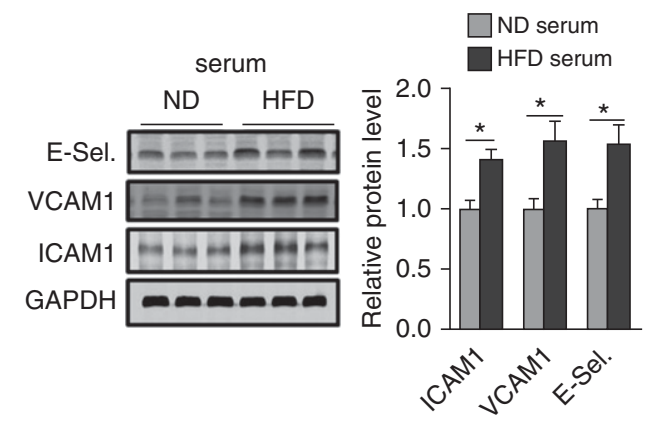

$\mathbf{F}$

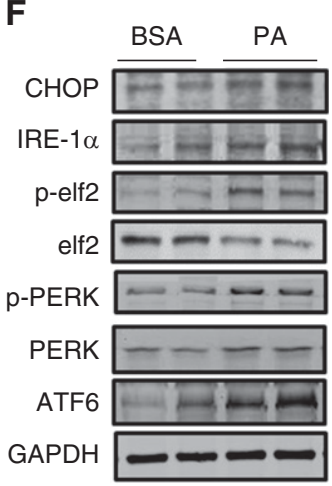

G

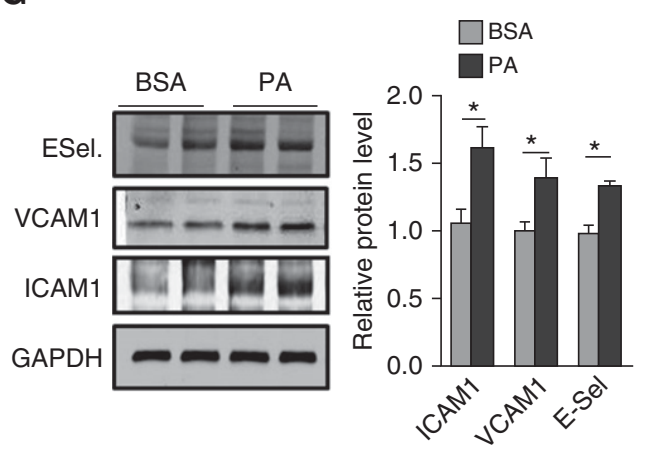

H

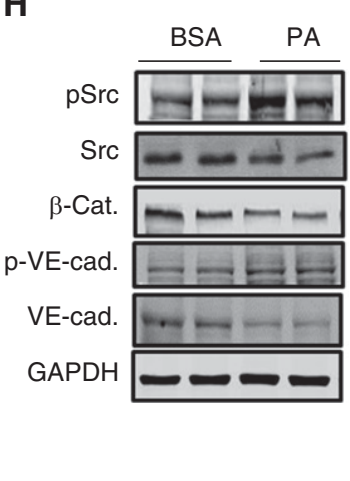

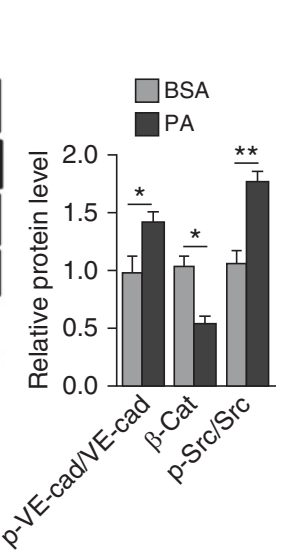

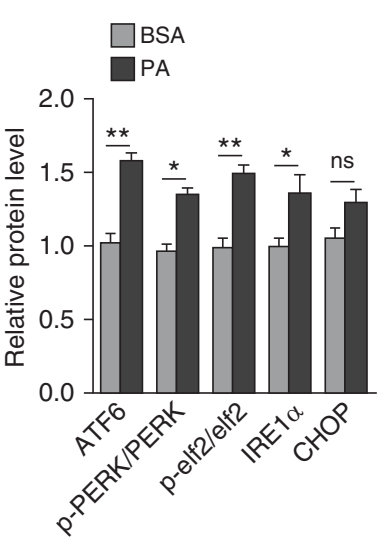

Figure 2. Saturated fatty acids induce ER stress and cause lung endothelial cell dysfunction. (A) Serum free fatty acid (FFA) levels at 0 and 14 weeks after mice were fed a control or HFD ( $a=8$; ${ }^{\star *} P<0.01$, HFD versus ND group). Western blot analysis for $(B)$ ER stress markers, ATF6, PERK, p-PERK, elF2, p-elF2, and IRE1 $\alpha\left({ }^{\star} P<0.05\right),(C)$ intercellular adhesion molecule 1 (ICAM1) $\left({ }^{\star} P<0.05\right)$, vascular cell adhesion molecule 1 (VCAM1), and E-selectin (E-Sel.), and ( $D$ ) vascular endothelial (VE)-cadherin, $p$-VE-cadherin, $\beta$-catenin ( $\beta$-Cat.), sarcoma kinase (Src), and pSrc in lung microvascular endothelial cells cultured with serum from lean or obese mice for 24 hours. (E) Transcript levels for GRP78 and CHOP in lung microvascular endothelial cells cultured with palmitic acid (PA) plus bovine serum albumin (BSA) or BSA alone for 24 hours. (F) Western blot analysis for ER stress markers, ATF6, PERK, p-PERK, elF2, p-elF2, IRE1 $\alpha$, and CHOP in lung microvascular endothelial cells cultured with PA or BSA for 24 hours. (G) Protein levels for ICAM1, VCAM1, and E-selectin PA- or BSA-exposed lung microvascular endothelial cells. (H) Protein levels for VE-cadherin, $p-V E$-cadherin, $\beta$-catenin, Src, and pSrc in PA- or BSA-exposed cells. Western blots are representative of at least two different images, and results of densitometry analysis are depicted in bar graphs ${ }^{\star} P<0.05$ and ${ }^{\star \star} P<0.01$, PA versus BSA). Data are expressed as mean $( \pm \mathrm{SE})$. The statistical significance was assessed using a Student's unpaired $t$ test. 
A

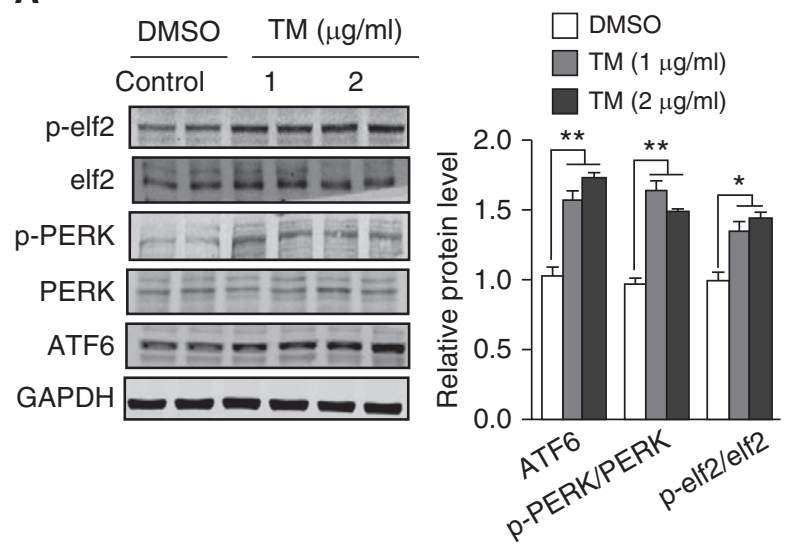

B

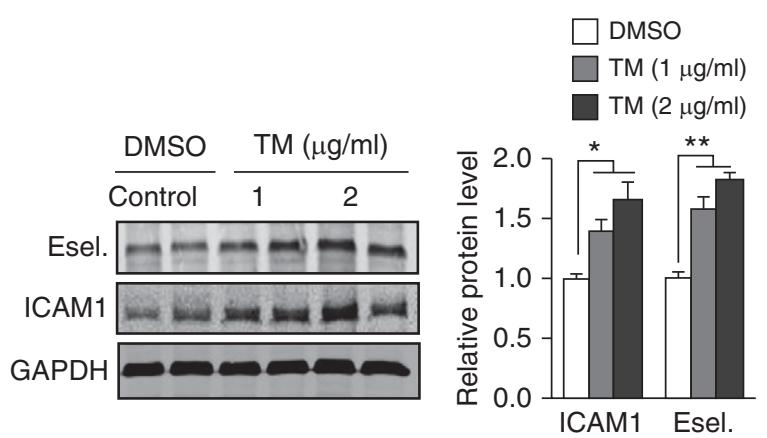

C

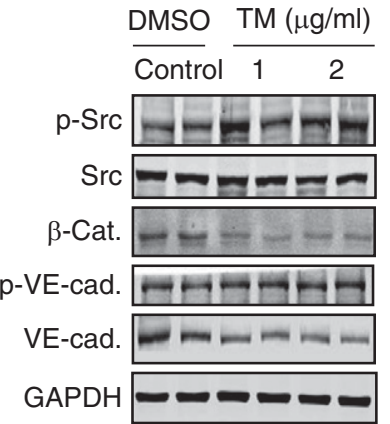

D
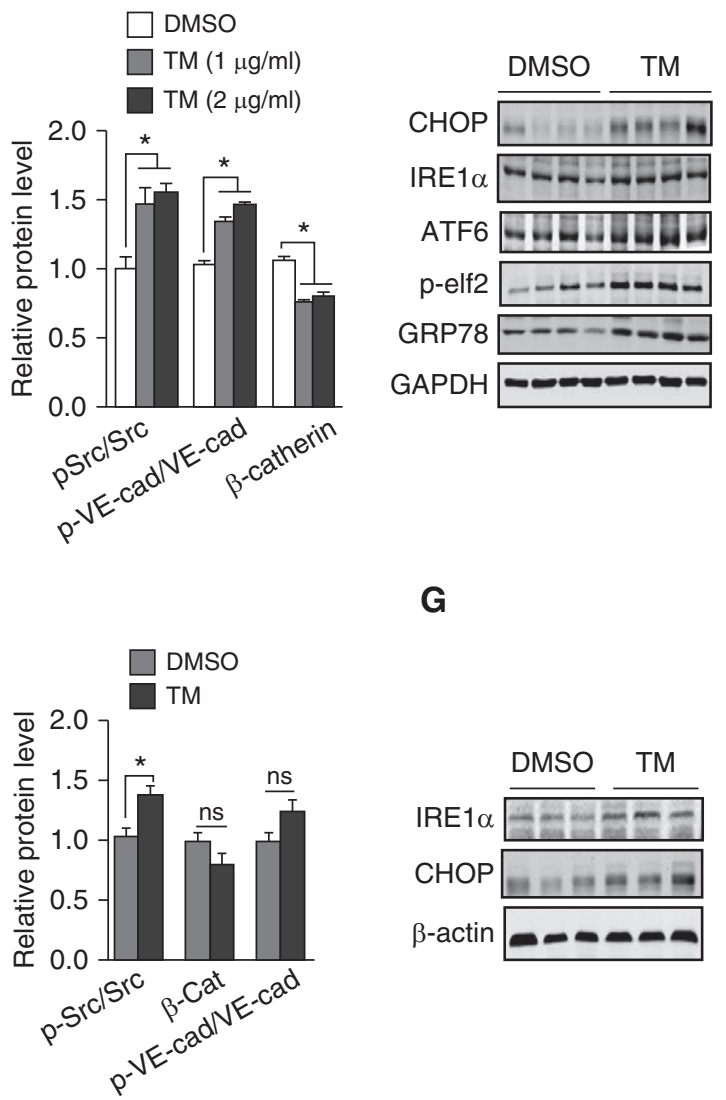

G

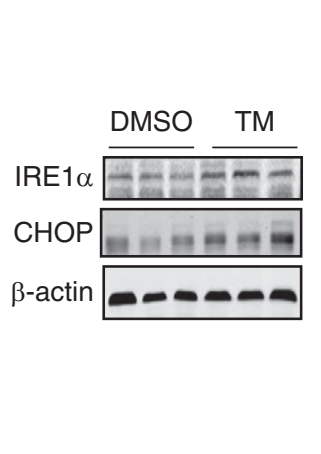

E

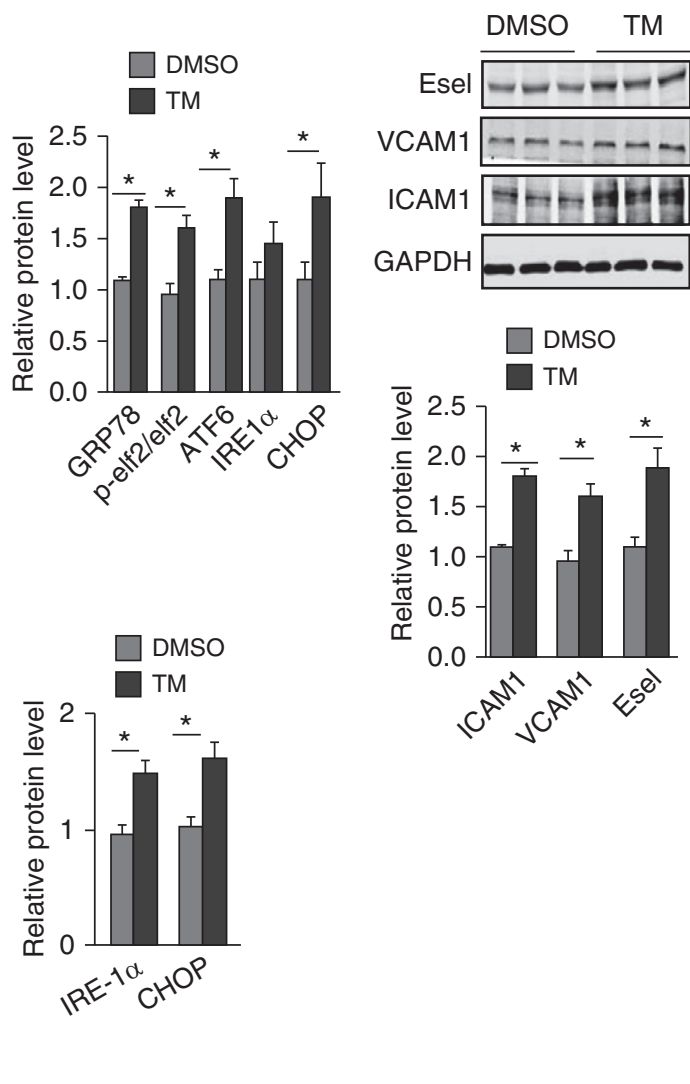

Figure 3. Tunicamycin causes endothelial dysfunction in lung endothelial cells and in whole-lung tissues. Western blot analyses for ER stress markers, endothelial adhesion proteins, and junctional proteins in cultured lung microvascular endothelial cells $(A-C)$ and whole-lung tissues $(D-F)$. (G) Western blot analysis for ER stress markers in freshly isolated endothelial cells from the lungs of DMSO- or tunicamycin (TM)-exposed mice. Images are representative of two different blots, and results of densitometry analysis are provided in bar graphs $\left({ }^{\star} P<0.05\right.$ and ${ }^{* \star} P<0.01$ versus ND serum, respectively). Data are expressed as mean ( $\pm \mathrm{SE})$, and statistical significance was assessed using a Student's unpaired $t$ test. Esel, E-selectin.

Furthermore, we observed functional improvements in endothelial barrier properties, as measured by decreased fluorescein isothiocyanate (FITC)-labeled dextran transport across cell monolayers after exposure to LPS (a trigger of ALI; Figure 4E).
We then tested whether 4-PBA could reverse the effects of obesity on the lung endothelium in vivo. We administered daily 4-PBA to diet-induced obese mice for 14 days and measured the expression of UPR proteins and endothelial-specific markers in the lung. Treatment with 4-PBA reduced the expression of ER stress markers, ATF6, p-PERK/PERK, IRE1 $\alpha$, pelF $2 \alpha /$ elF2 $\alpha$, CHOP, and GRP78, relative to expression levels in the lungs of dietinduced obese control mice (Figures 5A 
A

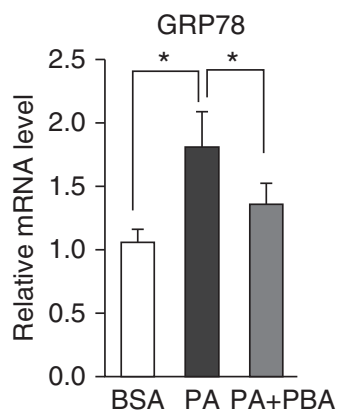

C

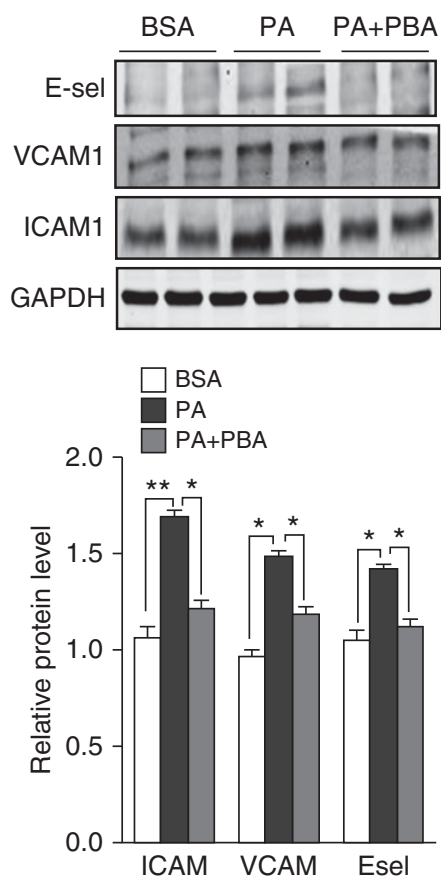

B
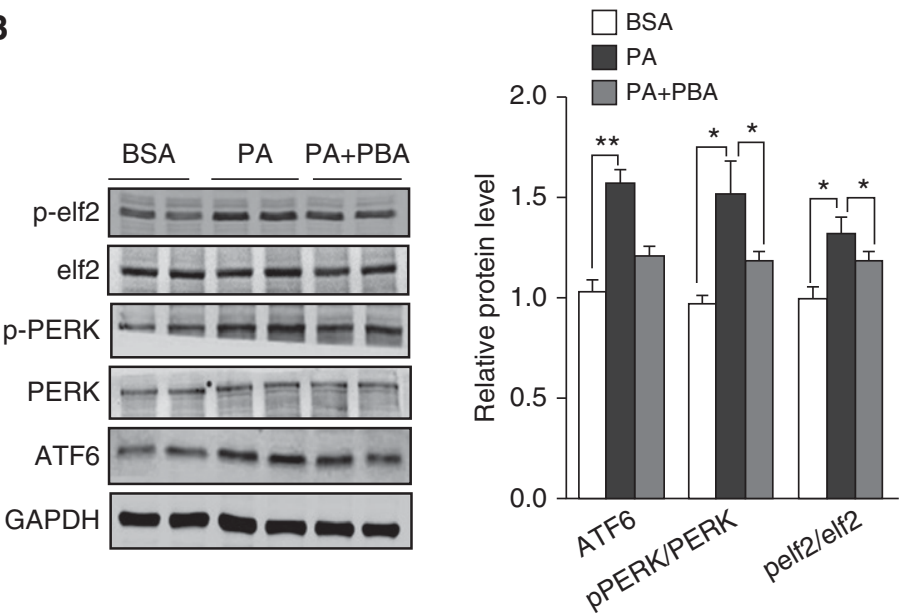

E

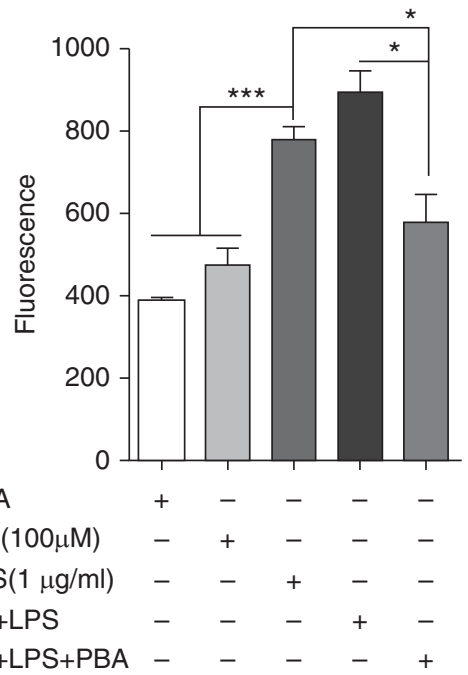

Figure 4. 4-phenylbutyric acid (4-PBA) treatment attenuates PA-induced endothelial cell dysfunction. (A) Transcript levels for ER stress markers, GRP78 and $\mathrm{CHOP}$, in lung microvascular cells cultured with PA-BSA, PA-BSA plus 4-PBA, or BSA alone. Western blot analysis for (B) ER stress markers, ATF6, PERK, p-PERK, elF2, and p-elF2, (C) vascular adhesion markers, ICAM1, VCAM1, and E-selectin, and (D) junctional proteins, VE-cadherin, $\beta$-catenin, and pSrc in lung microvascular endothelial cells cultured with PA-BSA alone, PA-BSA plus 4-PBA, or BSA alone. Each image is representative of two different Western blots, and results of densitometry analysis are provided in bar graphs $\left({ }^{\star} P<0.05,{ }^{\star \star} P<0.01\right.$, and ${ }^{\star \star \star} P<0.001$ PA versus PA + PBA) (E) Fluorescein isothiocyanate (FITC) dextran permeability assay. 4-PBA treatment reduced the quantity of FITC-dextran recovered in lower chamber of a Transwell system. This experiment was repeated three times. Data are expressed as mean ( \pm SE) $\left({ }^{\star} P<0.05\right.$ and $\left.{ }^{* \star *} P<0.001\right)$. The statistical significance was assessed using a one-way ANOVA followed by Tukey's post hoc analysis.

and 5B). Similarly, 4-PBA-treated obese mice had reduced expression of ICAM1, VCAM1, E-selectin, and p-VEcadherin/VE-cadherin, and enhanced expression of $\beta$-catenin compared with untreated obese mice (Figures $5 \mathrm{C}$ and 5D). Taken together, these findings indicate that 4-PBA treatment restores endothelial homeostasis in the lungs of diet-induced obese mice.

We next assessed whether the net effect of 4-PBA on the lung endothelium 
A

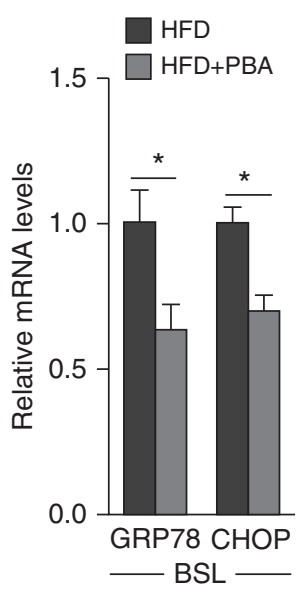

B

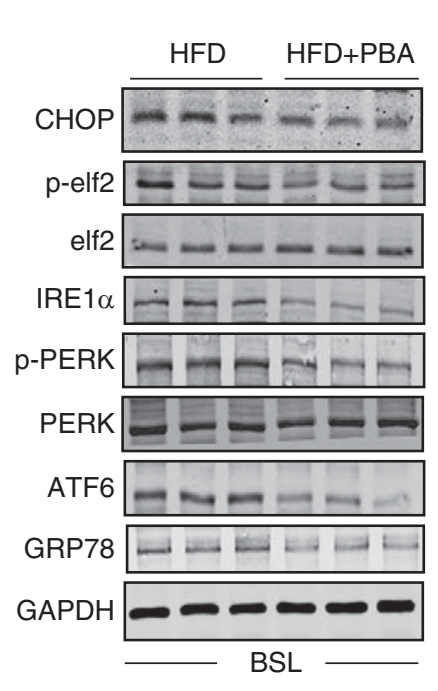

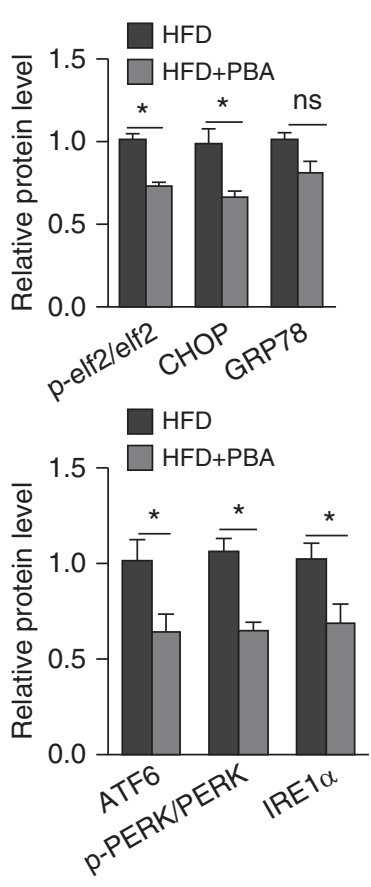

E

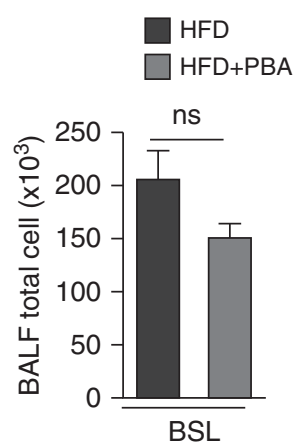

$\mathbf{F}$
C
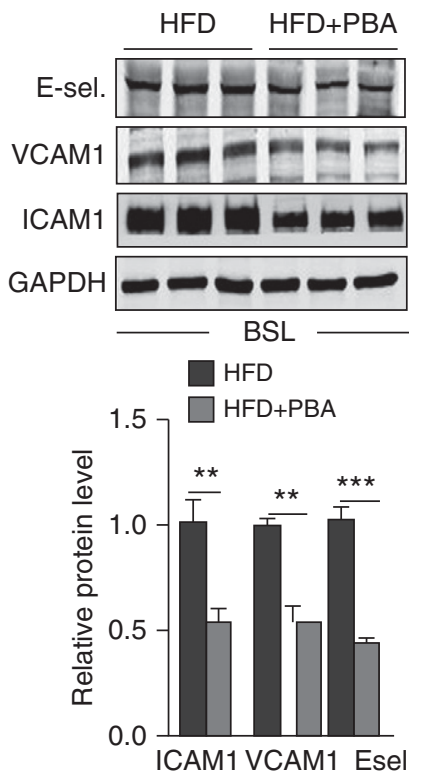

D

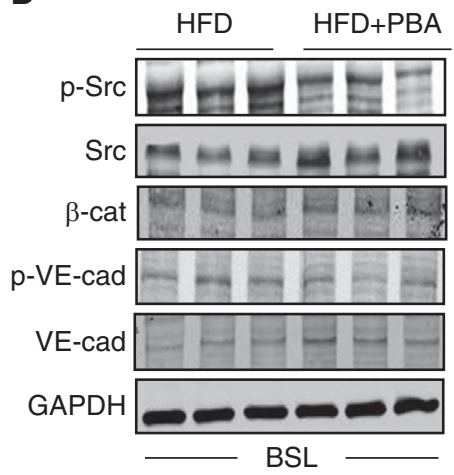

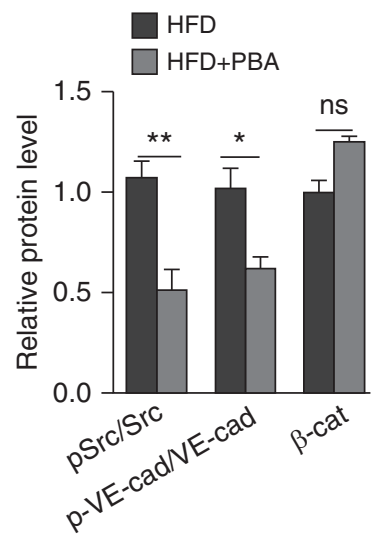

Figure 5. Treatment with 4-PBA restores endothelial homeostasis in the lungs of diet-induced obese mice. (A) Transcript levels for GRP78 and CHOP in the lungs of diet-induced obese mice treated with or without 4-PBA. Western blot analysis for $(B)$ ER stress markers, ATF6, PERK, p-PERK, elF2, p-elF2, IRE1 $\alpha, \mathrm{CHOP}$, and GRP78, (C) endothelial adhesion markers, ICAM1, VCAM1, and E-selectin, and (D) junctional adherens proteins, VE-cadherin, $p-V E$-cadherin, $\beta$-catenin, Src, and pSrc in the lungs of diet-induced obese mice treated with or without 4-PBA. All images are representative of two different blots, and densitometry analyses are shown in bar graphs $\left({ }^{\star} P<0.05,{ }^{\star \star} P<0.01\right.$, and ${ }^{\star \star \star} P<0.001, \mathrm{HFD}$ versus HFD + PBA). (E and $\left.F\right)$ Total cell count and total protein concentration in the bronchoalveolar lavage fluid (BALF) of diet-induced obese mice pretreated with 4-PBA or without 4-PBA for 14 days. Data are expressed as mean $( \pm \mathrm{SE})$. The statistical significance was assessed using a Student's unpaired $t$ test.

results in reduced susceptibility to ALI in diet-induced obese mice. We exposed control and 4-PBA-treated, diet-induced obese mice to intratracheal LPS, and then measured pulmonary injury and inflammation. We observed that treatment with 4-PBA reduced expression of UPR transcripts and proteins in obese mice exposed to LPS (Figures 6A and 6B). These findings were associated with additional protein expression changes, indicating protection from LPS-induced ALI, including reduced expression of ICAM1, VCAM1, and E-selectin, decreased $\mathrm{pSrc} / \mathrm{Src}$ and $\mathrm{p}-\mathrm{VE}$-cadherin/VE-cadherin ratios, and enhanced expression of $\beta$-catenin (Figures $6 \mathrm{C}$ and $6 \mathrm{D}$ ). Consistent with these biochemical findings, we observed that treatment with 4-PBA markedly reduced lung inflammation in response to LPS, as measured by the quantity of neutrophils and total immune cells recovered from BAL fluid, the number of granulocyte-1 (Gr-1)-positive cells in lung tissue sections, and levels of proinflammatory cytokines, TNF- $\alpha$ and IL- 6 , in whole-lung digests (Figures 7A-7E). The reduction in lung inflammation was associated with reduced pulmonary vascular leakage, as measured by: (1) total protein and IgM concentrations in 
A

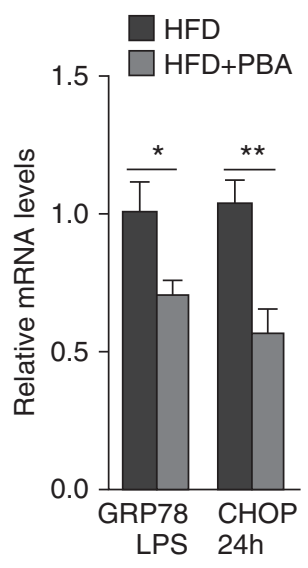

B

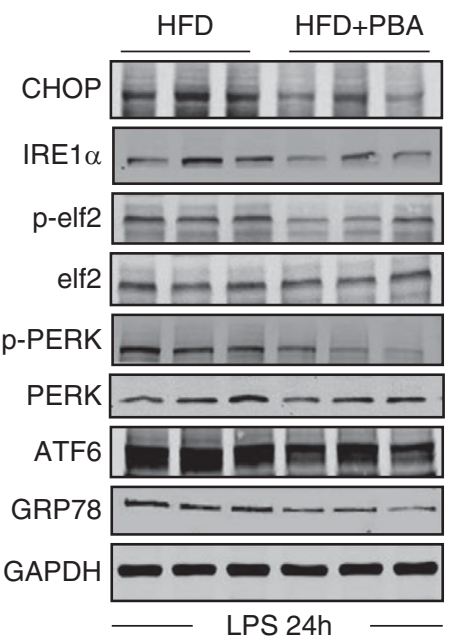

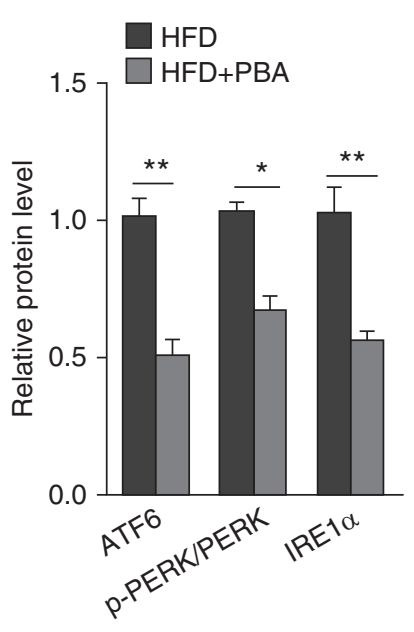

D

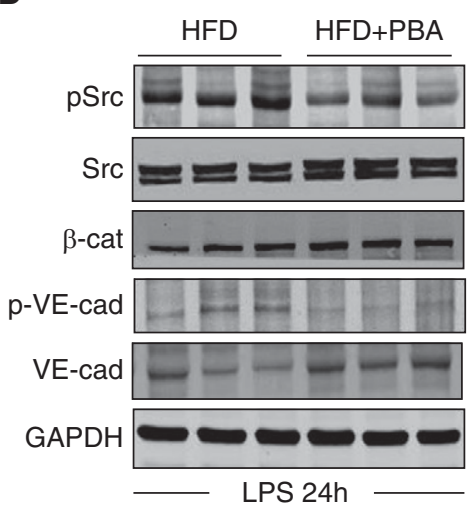

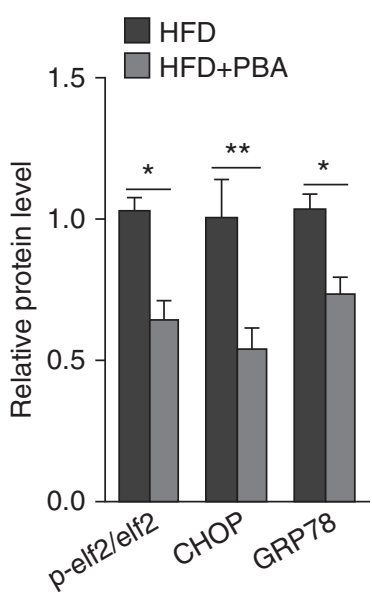

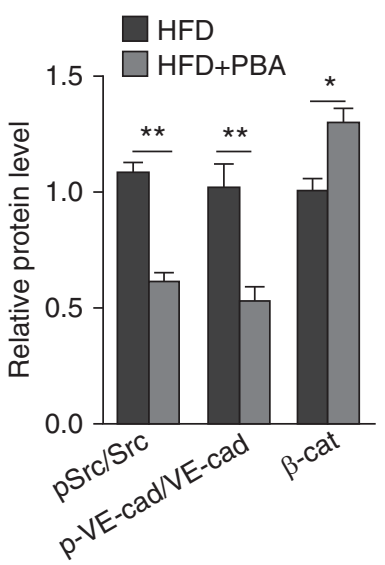

Figure 6. Treatment with 4-PBA reduces ER stress and attenuates endothelial dysfunction in the lungs of LPS-injured, diet-induced obese mice. (A) Transcript levels for GRP78 and CHOP in the lungs of LPS-injured, diet-induced obese mice treated with or without 4-PBA. Western blot analysis for (B) ER stress markers, ATF6, PERK, p-PERK, elF2, p-elF2, IRE1 $\alpha$, CHOP, and GRP78, (C) vascular adhesion markers, ICAM1, VCAM1, and E-selectin, and (D) total and phosphorylated levels of the junctional adherens proteins, VE-cadherin, $\beta$-catenin, and Src, in the lungs of LPS-injured, diet-induced obese mice treated with or without 4-PBA. All images are representative of two different blots, and densitometry analyses are shown in bar graphs ${ }^{*} P<0.05$ and ${ }^{\star \star} P<0.01, \mathrm{HFD}$ versus HFD + PBA). Data are expressed as mean ( $\left.\pm \mathrm{SE}\right)$. The statistical significance was assessed using a Student's unpaired $t$ test.

the BAL fluid; (2) the quantity of Evans blue dye extravasation into lungs; (3) the ratio of lung wet-to-dry weight; and (4) the quantity of fluid surrounding blood vessels in histological lung samples (Figures 7F-7J). Together, these findings indicate that 4-PBA treatment reduces the susceptibility of diet-induced obese mice to LPS-induced ALI.

\section{Discussion}

Obesity is a risk factor for ARDS, a form of ALI. This work examined the mechanisms by which obesity alters pulmonary endothelial homeostasis, thus predisposing to ALI. We demonstrated that induction of ER stress in the pulmonary endothelium is central to the pulmonary vascular dysfunction in diet-induced obese mice. Our mechanistic studies indicate that high levels of saturated fatty acids in the circulation of diet-induced obese mice may contribute to the development of ER stress in their lung endothelium. ER stress, in turn, leads to a wide range of downstream consequences that impair endothelial functions and predispose to ALI. We demonstrated that reducing ER stress restores endothelial homeostasis and reduces the susceptibility to ALI in vivo in obese mice. These findings provide important mechanistic insight into the pathogenesis of ALI in obese individuals. Furthermore, our data suggest that therapies that reduce ER stress might prevent ARDS in the obese.

The benefits of a low-fat diet on cardiovascular health are well documented (23). In addition, it has been suggested that Mediterranean-style diets, rich in mono-unsaturated fatty acids, may be cardioprotective, possibly stemming from the antiinflammatory and insulinsensitizing properties of mono-unsaturated fatty acids on target tissues (24). Here, we demonstrated that mono-unsaturated 
A

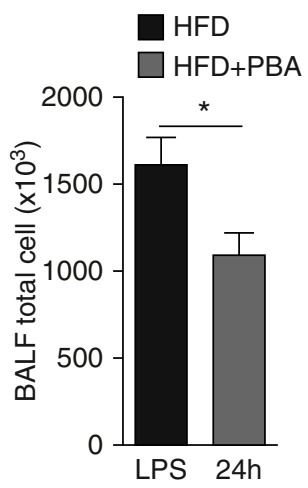

D

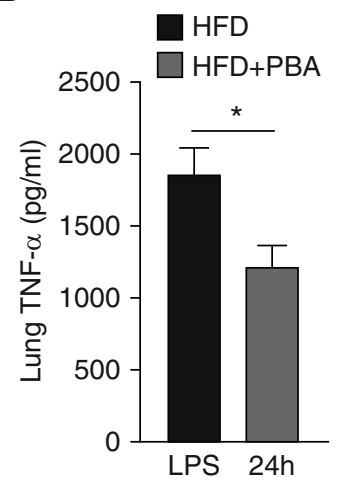

B

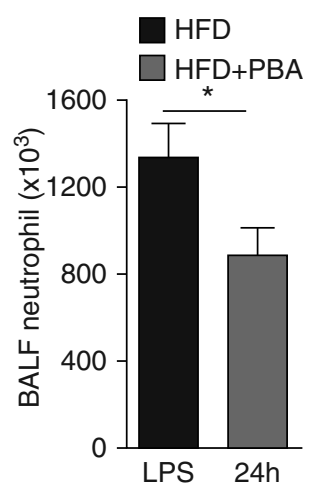

E

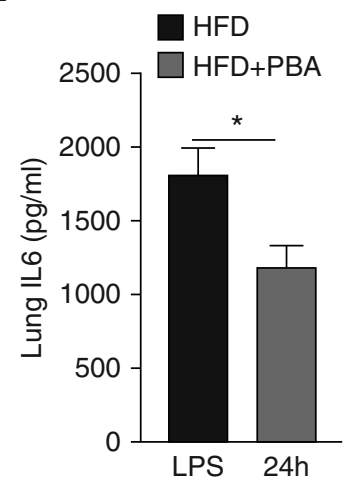

C

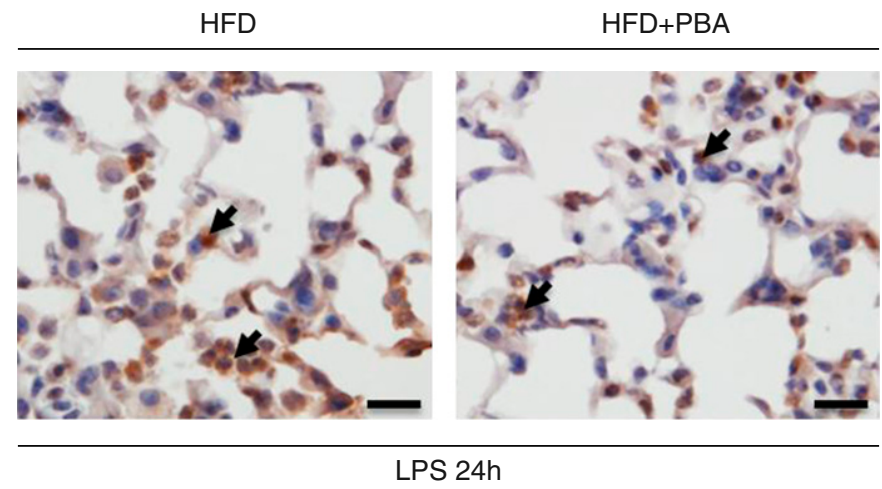

F

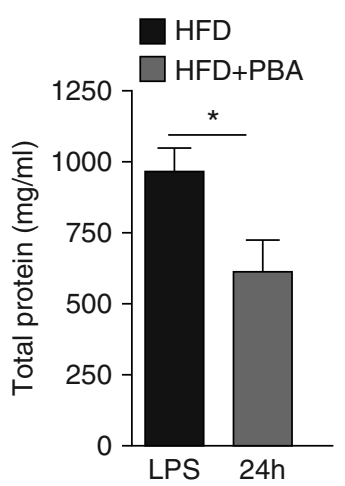

G

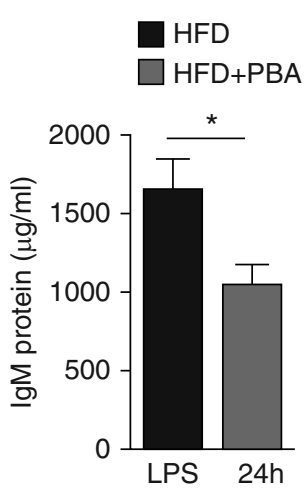

H

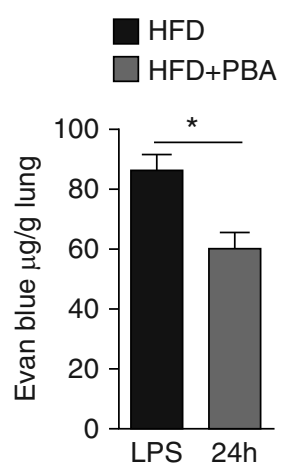

I

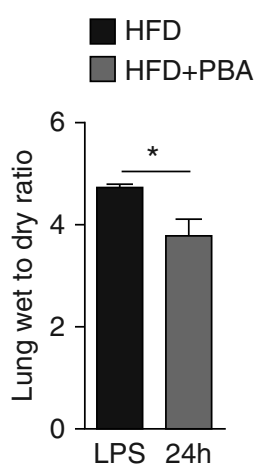

J

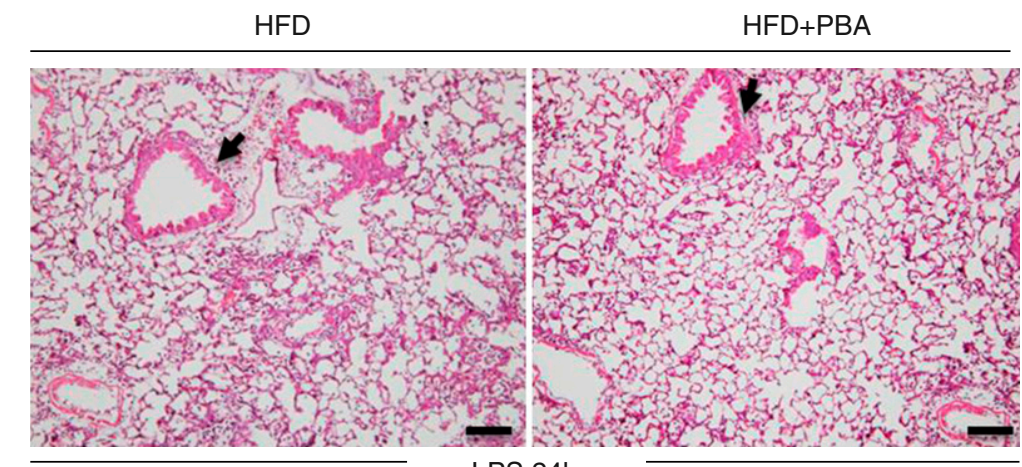

LPS 24h

Figure 7. Treatment with 4-PBA ameliorates LPS-induced lung injury in diet-induced obese mice. (A and B) Total cell counts and neutrophil cell counts in BALF of LPS-injured, diet-induced obese mice treated with or without 4-PBA. (C) Granulocyte-1 staining (black arrows) of lung sections from LPS-injured, diet-induced obese mice treated with or without 4-PBA. Scale bars: $100 \mu \mathrm{m}$. ( $D$ and E) ELISA for TNF- $\alpha$ and IL-6 in lungs of LPS-induced in HFD mice treated with or without PBA. ( $F$ and $G$ ) Total protein and IgM concentration in BALF of LPS-injured, diet-induced obese mice treated with or without 4-PBA. ( $H$ and $I$ ) Evans blue dye concentration and lung wet-to-dry ratio in the lungs of LPS-injured, diet-induced obese mice treated with or without 4-PBA. (J) Representative hematoxylin and eosin-stained lung sections from LPS-injured obese mice receiving PBA treatment or PBS. Perivascular edema (black arrows) was decreased in obese mice that received 4-PBA when compared with controls. Scale bars: $500 \mu \mathrm{m} .{ }^{*} P<0.05, \mathrm{HFD}$ versus HFD + PBA. Data are expressed as mean $( \pm \mathrm{SE})$. The statistical significance was assessed using a Student's unpaired $t$ test.

fatty acids have a protective effect on the lung endothelium, reverse the effects of saturated fatty acids on ER function, and attenuate pulmonary inflammation in response to LPS exposure. These findings suggest that the possibility that dietary approaches that reduce systemic levels of saturated fatty acids and/or increase levels of mono-unsaturated fatty acids might enhance endothelial barrier function and reduce the severity of pulmonary vascular leakage in patients at risk for ARDS.
Clinical studies have demonstrated that intravenous infusion of lipid emulsions, part of the parenteral nutritional support of critically ill patients, can trigger or exacerbate ARDS, leading to impaired oxygenation and increased pulmonary 
artery pressures $(25,26)$. The pathogenesis of this effect has not been determined, although it has been hypothesized that the inflammatory end-products of lipid metabolism might contribute to the observed susceptibility of the lung to ARDS in affected patients. Our work suggests that an alternative mechanism by which high levels of circulating saturated fatty acids may predispose to ALI, potentially, by triggering endothelial cell ER stress, which, in turn, adversely affects pulmonary endothelial function. Interestingly, most intralipid formulations contain relatively low concentrations of saturated fatty acids (10-15\% PA) (27); whether such concentrations are sufficient to impair pulmonary endothelial function in lean or obese humans in the critical care setting remains to be tested. Whether the ill effects of infused saturated fatty acids could be attenuated by adjusting levels of infused unsaturated fatty acids (or other factors that reduce endothelial ER stress) is similarly unknown.

Currently, we do not know which of the known UPR pathways are responsible for inducing leukocyte adhesion proteins and repressing junctional adherens proteins in the pulmonary endothelium of obese lungs. In tissues considered to be most affected by obesity (e.g., adipose tissue, liver), a major consequence of chronic activation of the UPR is up-regulation in inflammatory pathways. For example, PERK-mediated phosphorylation of elF2 has been shown to increase NF- $\kappa \mathrm{B}$ signaling by preferentially inhibiting the translation of $\mathrm{IkB}$, a cytosolic inhibitor of NF- $\kappa B(28,29)$. In addition, the IRE1 $\alpha$ limb of the UPR has been shown to augment NF- $\mathrm{KB}$ signaling and to enhance $\mathrm{c}$-jun $\mathrm{N}$-terminal-activated kinase-activator protein-1 signaling pathways (30). Because NF- $\kappa \mathrm{B}$ and $\mathrm{c}$-jun $\mathrm{N}$-terminal-activated kinase-activator protein-1 drive expression of endothelial adhesion proteins (E-selectin, ICAM1) and promote expression of various cytokines (e.g., TNF- $\alpha$, IL6) linked to endothelial barrier disruption in the systemic vasculature, it is possible that similar pathways are operative in the pulmonary endothelium in response to ER stress (31-33). That said, future studies are needed to confirm which pathways are involved in causing lung endothelial dysfunction and whether blocking one or more of these pathways is required to restore lung endothelial health and to protect the human lung from acute injury.

Our study demonstrates that ER stress-reducing agents enhance endothelial barrier functions in the lungs of obese mice. If ER stress represents a common pathway leading to endothelial dysfunction, then this therapeutic approach may have clinical implications extending beyond the treatment of ARDS. It seems reasonable, for example, to assess whether ER stress contributes to the pathogenesis of conditions leading to hydrostatic pulmonary edema, such as congestive heart failure (34). Likewise, it will be important to test whether 4-PBA reduces vascular leak from systemic blood vessels in edematous conditions, such as cirrhosis, kidney failure, or morbid obesity.

Although our work has demonstrated that 4-PBA reduces ER stress in the lung endothelium, we recognize that 4-PBA may have effects on alternative tissues in the lung. Relevant to ARDS, it would be interesting to know whether obesity induces ER stress in the distal pulmonary epithelium and whether this contributes to the increase in fluid leakage into the lung after injury. In this case, treatment with 4-PBA may have dual effects, simultaneously enhancing barrier functions in the endothelium and epithelium of the lung. It is also important to mention that PBA treatment has been shown to ameliorate ALI in lean mice after LPS administration (35). These findings, along with our findings, suggest that PBA treatment might be effective in both the prevention and treatment of ALI.

In summary, we have shown that ER stress plays an important role in impairing pulmonary endothelial function in dietinduced obese mice, and that these effects may be due, at least in part, to elevated exposure to saturated fatty acids in obese mice, and that small-molecule inhibitors of ER stress can restore endothelial homeostasis and attenuate the severity of ALI in obese mice. These findings provide a rationale for testing similar therapeutic approaches in humans.

Author disclosures are available with the text of this article at www.atsjournals.org.

\section{References}

1. Gajic O, Dabbagh O, Park PK, Adesanya A, Chang SY, Hou P, Anderson H III, Hoth JJ, Mikkelsen ME, Gentile NT, et al.; U.S. Critical Illness and Injury Trials Group: Lung Injury Prevention Study Investigators (USCIITG-LIPS). Early identification of patients at risk of acute lung injury: evaluation of lung injury prediction score in a multicenter cohort study. Am J Respir Crit Care Med 2011;183: 462-470.

2. Gong MN, Bajwa EK, Thompson BT, Christiani DC. Body mass index is associated with the development of acute respiratory distress syndrome. Thorax 2010;65:44-50.

3. Shah D, Romero F, Duong M, Wang N, Paudyal B, Suratt BT, Kallen CB, Sun J, Zhu Y, Walsh K, et al. Obesity-induced adipokine imbalance impairs mouse pulmonary vascular endothelial function and primes the lung for injury. Sci Rep 2015;5:11362.

4. Kershaw EE, Flier JS. Adipose tissue as an endocrine organ. J Clin Endocrinol Metab 2004;89:2548-2556.

5. Jensen MD, Haymond MW, Rizza RA, Cryer PE, Miles JM. Influence of body fat distribution on free fatty acid metabolism in obesity. $J$ Clin Invest 1989;83:1168-1173.

6. Boden G. Obesity and free fatty acids. Endocrinol Metab Clin North Am 2008;37:635-646,(viii-ix.).
7. Santomauro AT, Boden G, Silva ME, Rocha DM, Santos RF, Ursich MJ, Strassmann PG, Wajchenberg BL. Overnight lowering of free fatty acids with acipimox improves insulin resistance and glucose tolerance in obese diabetic and nondiabetic subjects. Diabetes 1999;48: 1836-1841.

8. Han J, Kaufman RJ. The role of ER stress in lipid metabolism and lipotoxicity. J Lipid Res 2016;57:1329-1338.

9. Fu S, Yang L, Li P, Hofmann O, Dicker L, Hide W, Lin X, Watkins SM, Ivanov AR, Hotamisligil GS. Aberrant lipid metabolism disrupts calcium homeostasis causing liver endoplasmic reticulum stress in obesity. Nature 2011;473: 528-531.

10. Puri P, Mirshahi F, Cheung O, Natarajan R, Maher JW, Kellum JM, Sanyal AJ. Activation and dysregulation of the unfolded protein response in nonalcoholic fatty liver disease. Gastroenterology 2008; 134:568-576.

11. Hotamisligil GS. Endoplasmic reticulum stress and atherosclerosis. Nat Med 2010;16:396-399.

12. Ozcan U, Cao Q, Yilmaz E, Lee AH, Iwakoshi NN, Ozdelen E, Tuncman G, Görgün C, Glimcher LH, Hotamisligil GS. Endoplasmic reticulum stress links obesity, insulin action, and type 2 diabetes. Science 2004;306:457-461.

13. Zhang K, Kaufman RJ. From endoplasmic-reticulum stress to the inflammatory response. Nature 2008;454:455-462. 
14. Cimellaro A, Perticone M, Fiorentino TV, Sciacqua A, Hribal ML. Role of endoplasmic reticulum stress in endothelial dysfunction. Nutr Metab Cardiovasc Dis 2016;26:863-871.

15. Shah D, Romero F, Summer R. Diet-induced obesity induces endoplasmic reticulum stress in the lung endothelium and predispose to Ips induced acute lung injury [abstract]. Am J Respir Crit Care Med 2016;193:A7868.

16. Lawson WE, Cheng DS, Degryse AL, Tanjore H, Polosukhin VV, Xu XC, Newcomb DC, Jones BR, Roldan J, Lane KB, et al. Endoplasmic reticulum stress enhances fibrotic remodeling in the lungs. Proc Natl Acad Sci USA 2011;108:10562-10567.

17. Konter JM, Parker JL, Baez E, Li SZ, Ranscht B, Denzel M, Little FF, Nakamura K, Ouchi N, Fine A, et al. Adiponectin attenuates lipopolysaccharide-induced acute lung injury through suppression of endothelial cell activation. J Immunol 2012;188:854-863.

18. Shah D, Romero F, Stafstrom W, Duong M, Summer R. Extracellular ATP mediates the late phase of neutrophil recruitment to the lung in murine models of acute lung injury. Am J Physiol Lung Cell Mol Physiol 2014;306:L152-L161.

19. Shah D, Romero F, Zhu Y, Duong M, Sun J, Walsh K, Summer R. C1q deficiency promotes pulmonary vascular inflammation and enhances the susceptibility of the lung endothelium to injury. J Biol Chem 2015; 290:29642-29651.

20. Romero F, Shah D, Duong M, Stafstrom W, Hoek JB, Kallen CB, Lang $\mathrm{CH}$, Summer R. Chronic alcohol ingestion in rats alters lung metabolism, promotes lipid accumulation, and impairs alveolar macrophage functions. Am J Respir Cell Mol Biol 2014;51: 840-849.

21. Opie LH, Walfish PG. Plasma free fatty acid concentrations in obesity. N Engl J Med 1963;268:757-760.

22. Tampakakis E, Tabit CE, Holbrook M, Linder EA, Berk BD, Frame AA, Bretón-Romero R, Fetterman JL, Gokce N, Vita JA, et al. Intravenous lipid infusion induces endoplasmic reticulum stress in endothelial cells and blood mononuclear cells of healthy adults. J Am Heart Assoc 2016;5:5.

23. Oh K, Hu FB, Manson JE, Stampfer MJ, Willett WC. Dietary fat intake and risk of coronary heart disease in women: 20 years of follow-up of the Nurses' Health Study. Am J Epidemiol 2005;161:672-679.
24. Estruch R, Ros E, Martínez-González MA. Mediterranean diet for primary prevention of cardiovascular disease. N Engl J Med 2013;369: 676-677.

25. Lekka ME, Liokatis S, Nathanail C, Galani V, Nakos G. The impact of intravenous fat emulsion administration in acute lung injury. $A m \mathrm{~J}$ Respir Crit Care Med 2004;169:638-644.

26. Venus B, Smith RA, Patel C, Sandoval E. Hemodynamic and gas exchange alterations during intralipid infusion in patients with adult respiratory distress syndrome. Chest 1989;95:1278-1281.

27. Fell GL, Nandivada $P$, Gura KM, Puder M. Intravenous lipid emulsions in parenteral nutrition. Adv Nutr 2015;6:600-610.

28. Harding HP, Zhang Y, Bertolotti A, Zeng H, Ron D. Perk is essential for translational regulation and cell survival during the unfolded protein response. Mol Cell 2000;5:897-904.

29. Deng J, Lu PD, Zhang Y, Scheuner D, Kaufman RJ, Sonenberg N, Harding HP, Ron D. Translational repression mediates activation of nuclear factor kappa B by phosphorylated translation initiation factor 2. Mol Cell Biol 2004;24:10161-10168.

30. Walter $P$, Ron $D$. The unfolded protein response: from stress pathway to homeostatic regulation. Science 2011;334:1081-1086.

31. Desai TR, Leeper NJ, Hynes KL, Gewertz BL. Interleukin-6 causes endothelial barrier dysfunction via the protein kinase $\mathrm{C}$ pathway. J Surg Res 2002;104:118-123.

32. Chen $\mathrm{Y}, \mathrm{Wu} Z$, Zhao S, Xiang R. Chemical chaperones reduce ER stress and adipose tissue inflammation in high fat diet-induced mouse model of obesity. Sci Rep 2016;6:27486.

33. Melotti $P$, Nicolis E, Tamanini A, Rolfini R, Pavirani A, Cabrini G. Activation of NF-kB mediates ICAM-1 induction in respiratory cells exposed to an adenovirus-derived vector. Gene Ther 2001;8:1436-1442.

34. Curtis JP, Selter JG, Wang Y, Rathore SS, Jovin IS, Jadbabaie F, Kosiborod M, Portnay EL, Sokol SI, Bader F, et al. The obesity paradox: body mass index and outcomes in patients with heart failure. Arch Intern Med 2005;165:55-61.

35. Kim HJ, Jeong JS, Kim SR, Park SY, Chae HJ, Lee YC. Inhibition of endoplasmic reticulum stress alleviates lipopolysaccharide-induced lung inflammation through modulation of NF-кB/HIF- $1 \alpha$ signaling pathway. Sci Rep 2013;3:1142. 